\title{
Determination of probiotic characteristics and resistance to biological barriers under in vitro gastrointestinal conditions in goat cheese produced using microencapsulated probiotic bacteria
}

\author{
Nazan KAVAS ${ }^{1}$ () , Gökhan KAVAS², Mustafa ATEŞ³, Muammer KAPLAN ${ }^{4}$, Gülçin ŞATIR ${ }^{5}$, Özer KINIK²
}

\begin{abstract}
The method of microencapsulation has been performed on the probiotic microorganisms (Lactobacillus paracasei and Bifidobacterium longum), which are used in conjunction with the starter cultures in white cheese production from goat's milk. For this purpose, 3 types of microcapsules, namely, one containing the probiotic bacteria and another symbiotic microcapsule containing the probiotic bacteria and fructooligosaccharides have been obtained in the study and the cheese containing these microcapsules were produced. The cheese samples have been stored at $+4^{\circ} \mathrm{C}$ for 180 days and during storage, loss in viabiality that might be consisted at in-vitro conditions at gastrointestinal system is analyzed. The present study revealed that probiotic bacteria at different bile concentrations gained resistance during maturation, and the rate of resistance was higher in prebiotic and protein-supported microencapsulated probiotic bacteria. The resistance of lactic acid bacteria used in cheese production to gastric secretions was lower than that of probiotic bacteria. The determination of hydrophobicity of bacteria revealed that Bifidobacterium longum had the highest hydrophobicity level followed by Lactococcus, which forms the cheese culture, while Lactobacillus paracasei had the lowest level. It was determined that the microencapsulation method reduced the viability losses of probiotic microorganisms in the gastrointestinal tract.
\end{abstract}

Keywords: goat cheese; microencapsulation; Bifidobacterium longum; Lactobacillus paracasei; biological barriers; simulated gastric digestion.

Pratical Application: Microencapsulation method reduced the viability losses of probiotic microorganisms in the gastrointestinal tract.

\section{Introduction}

Goat milk, which is the most used one in cheese production among milk products, has the quality of being a very common raw material used in cheese production (Popović-Vranješ et al., 2017; Barłowska et al., 2018; Mituniewicz-Małek et al., 2019; Herman-Lara et al., 2019). Probiotic microorganisms are regarded as functional food compounds; they can show important effects on stomach and bowel system of human beings; they can alert the immune system by having direct or indirect effect on bowel physiology and microbial ecology. For that purpose, it is seen that in order to protect and even increase the numbers of probiotic microorganisms in metabolism, the experiments done on some important factors have intensified (Sanders et al., 2018). It has been detected with a number of experiments, that probiotics are necessary for the prosperity and survival of the microorganisms which are healthy for the body. And, it has been emphasized that we should consume first probiotics and then prebiotics in order to support the healthy flora that exists in the bowels. Probiotics are food compounds that

selectively increase the breeding and/or activity of one or more healthy microorganisms that cannot be digested. Thus, "the manipulation of bowel bacteria" approach has come up and, today, the manipulation of the bowel flora with diet has become one the most popular working areas of nutrition science (Zendeboodi et al., 2020; Castro et al., 2015). The positive effects of probiotics on human health due to the synbiotic products produced with the usage of probiotics and prebiotics together are supported by prebiotics. Thus, probiotic microorganisms can stay alive for much longer and can provide more benefit for metabolism when they are consumed together with probiotics (Guarner, 2017). Microencapsulation technique provides important advantages for especially the production and protection of probiotic strains, the processing of the host food and, preserving of viability in gastrointestinal system (Rezaei et al., 2019). Microencapsulation is defined as the covering of the material in the condition of solid, liquid and gas, with a covering material which is either protein or carbon dioxide or both

${ }^{1}$ Ege University, Ege Higher Vocational School, Food Technology Programme, Izmir, Turkey

${ }^{2}$ Ege University, Faculty of Agriculture, Department of Dairy Technology, Izmir, Turkey

${ }^{3}$ Ege University, Faculty of Biology, Department of Basic and Endustrial Microbiology, Izmir, Turkey

${ }^{4}$ Tübitak Marmara Research Center, Kocaeli, Turkey

${ }^{5}$ Süleyman Demirel University, Faculty of Health Sciences, Department of Nutrition and Dietetics, Isparta, Turkey

*Corresponding author: nazan.kavas@ege.edu.tr 
in the shape of micro particulars. In the experiments done in recent years on microencapsulation technique, probiotic addition to covering material during microencapsulation in order to increase probiotic viability and snybiotic microcapsules are being worked on, and, on that case, success is achieved. For this purpose, in the researches, it is stated that prebiotics such as fructooligosaccharides, inulin, hi-maze starch, isomaltooligosaccharides in different proportions are widely used (Yao et al., 2020). In the experiments done related to the application of microencapsulation technique in milk and milk products, it is seen that there are many researches on different probiotic bacteria in especially yoghurt. But, it has been detected that there is not detailed and adequate work done on the application of microencapsulation method in probiotic goat cheese production. The aim of this study is the inspection of the in vitro viability of Lactobacillus casei and Bifidobacterium longum bacteria and microencapsulated probiotics by simulation gastrointestinal system, and, comparison of the loss of probiotics microencapsulation method applied in high acid environment and the loss of the probiotic microorganisms added as a single culture.

\section{Material and methods}

Lyophilized culture (Lactococcus lactis subsp. lactis + Lactococcus lactis ssp. cremoris) (Mayasan-Sacco) was used in the production of white cheese.

\subsection{Microencapsulation of probiotic microorganisms}

Microcapsules were prepared using the extrusion method in three forms. In this method, for Type 1 microcapsule extraction, $1 \%$ of probiotic culture mixture (Lactobacillus paracasei (Lafti L26 (DSM)) + Bifidobacterium longum (Lafti B22(DSM))) concentrate was pre-autoclaved (for 15 minutes at $121^{\circ} \mathrm{C}$ ) and mixed with $1 \%$ sodium alginate (Sigma Chemical USA). For Type 2 microcapsule extraction, fructooligosaccharide (FOS) was added to the sodium alginate + culture mixture. For Type 3 microcapsule extraction, inulin was added to the sodium alginate + culture mixture. The most efficient FOS and inulin ratio determined by Chen et al. (2005) was taken as reference, and the rate of prebiotics to be added was determined to be $2 \%$ in the preliminary trial. In addition, $1 \%$ digestible autoclaved pancreatic casein (Sigma Chemical USA) was added to stimulate the development of probiotics. The resulting mixture was slowly dropped into a sterile $0.1 \mathrm{M} \mathrm{CaCl}_{2}$ (Merck Darmstadt, Germany) solution using a syringe to obtain microcapsules. For the homogenous formation of capsules, the distance between the needle tip and beaker, which contained the $\mathrm{CaCl}_{2}$ solution, was $10 \mathrm{~cm}$ (Chen et al., 2006). After incubating for gelation process for 1 hour, the capsules were stored in a sterile $0.1 \%$ peptone solution at $+4{ }^{\circ} \mathrm{C}$.

\subsection{Cheese production}

In the cheese production process, goat milk was pasteurized at $75{ }^{\circ} \mathrm{C}$ for 15 seconds and divided into 7 equal groups. Then, for the production of cheese containing single probiotic culture, the relevant probiotic cultures (L. paracase $i$ and B. longum, 1:1) at a level of $1 \%$ were added to the cheese milk at $35^{\circ} \mathrm{C}-37^{\circ} \mathrm{C}$, and the cheese with SHPK code was obtained. For the production of cheese with prebiotic additives, in addition to probiotic cultures, FOS was added to milk to obtain the cheese with SHPK + F code, and inulin was added obtain the cheese with SHPK $+\mathrm{I}$ code. The cheese with MKP code was added with microcapsules containing only probiotic culture with $1 \%$ sodium alginate. The cheese with $\mathrm{MKP}+\mathrm{F}$ code was obtained by adding the microcapsules containing FOS The cheese with MKP+I code was obtained by adding microcapsules containing inulin .The cheese with $\mathrm{K}$ code was used as a control sample and was obtained using the traditional methods with no probiotic culture additives. Following the addition of probiotics and prebiotics, rennet was added to milk for coagulation, and the clot was subsequently broken and kept under pressure. After releasing the pressure and cutting, they were kept in 15\% (w/v) pasteurized brine for approximately 180 minutes. At the end of this period, they were taken out of the brine and placed into separate plastic cases for pre-maturation. The containers were subjected to maturation for 180 days at $4 \pm 1^{\circ} \mathrm{C}$.

\subsection{Probiotic microorganism and cheese culture count}

The B. longum count was measured in NPNL-MRS agar medium containing nalidixic acid, paromomycin sulfate, neomycin sulfate, and lithium chloride as inhibitory agents (Dave \& Shah, 1997). The L. paracasei count was measured using the MRS agar (Merck KGaA, Darmstadt, Germany) and was incubated under anaerobic conditions for 72 hours at $37^{\circ} \mathrm{C}$, (Gardiner et al., 2002). The starter culture count was measured using M17 agar (Merck KGaA, Darmstadt, Germany) and it was incubated under anaerobic conditions for 2 days at $37^{\circ} \mathrm{C}$.

\subsection{Culture medium and incubation conditions}

In order to release the microencapsulated probiotics and to examine the viability of probiotic microorganisms, the microcapsules were transferred to the phosphate buffer solution $(0.1 \mathrm{M}$ and $\mathrm{pH} 7)$ leading to a combination of phosphate and calcium, thereby impairing the capsule's gel integrity and allowing the bacteria in it to pass into the solution. Following this process, the released probiotics were cultured in MRS Broth at $37^{\circ} \mathrm{C}$.

\subsection{Bile salt deconjugation}

Bile salt deconjugation levels were determined by using Elliker Agar (DifcoTM Fluka, Steinheim,Switzerland) media containing $0.5 \%$ sodium salt (Sigma, Chemical Co. USA) (taurocholic acid,taurodeoxycholic acid, glycocholic acid and glicodeoxycholic acid). Transparent zones formed around the colonies after a 72 hours incubation at $37^{\circ} \mathrm{C}$ was regarded as deconjugation positive, and zone distributions on $8 \mathrm{~mm}$ was determined as strong positive (Vinderola \& Reinheimer, 2003). 


\subsection{Bile salt resistance}

For the determination of bile salt resistance, Elliker Broth (DifcoTM Fluka, Steinheim, Switzerland) media containing $0.3,0.5$, and $1 \%$ bile salt (Sigma, Chemical Co., USA) were used, following the incubation of $2 \%$ inoculated media for 24 hours at $37^{\circ} \mathrm{C}$, samples were measured at A 560 against the control sample and determined as viability \% (Vinderola \& Reinheimer, 2003).

\subsection{Hydrophobicity}

Hydrophobic properties of lactic acid bacteria were determined according to Perez et al., 1998 with some modifications. For this purpose, fresh cultures which were activated in an appropriate broth medium for 24 hours were centrifuged for 10 minutes at $8000 \mathrm{rpm}$. The supernatant obtained after centrifugation was washed twice with $50 \mathrm{mM} \mathrm{K}_{2} \mathrm{HPO}_{4}(\mathrm{pH}$ : 6.5) buffer, the optical density was adjusted to OD: 1 with using the same buffer. $6 \mathrm{~mL}$ bacteria solution, $2 \mathrm{~mL}$ buffer solution and $1.2 \mathrm{~mL}$ n-hexadecane (Merck, Germany) were taken in a tube and vortexed at high rpm for approximately 120 s. Following a 15 minute incubation at $37^{\circ} \mathrm{C}$, the samples were measured at $560 \mathrm{~nm}$ before and after the removal of the aqueous phase. Hydrophobic properties of the bacteria were calculated using the following formula.

$\%$ Hydrophobicity $=\left(\mathrm{A}_{0}-\left(\mathrm{A} / \mathrm{A}_{0}\right)\right) \times 100$

$\mathrm{A}_{0 \text { : }}$ absorbance before the removal of aqueous phase / A: absorbance after the removal of aqueous phase

\subsection{Tolerance to gastric liquids}

The resistance of bacteria to gastric fluids was determined based on the study by Vinderola \& Reinheimer (2003). A medium consisting of $0.3 \% \mathrm{w} / \mathrm{v}$ pepsin and $0.5 \% \mathrm{NaCl}$ adjusted to $\mathrm{pH} 2-3$, was used as the gastric fluid medium. Overnight cultures were centrifuged at $6,000 \mathrm{rpm}$ for 20 minutes at $5^{\circ} \mathrm{C}$ and washed twice with $50 \mathrm{mM} \mathrm{K}_{2} \mathrm{HPO}_{4}$ ( $\mathrm{pH}$ 6.5). The pellet was then suspended in $3 \mathrm{ml}$ of separate buffer, and $1 \mathrm{ml}$ of washed cell solution was again centrifuged at $12,000 \mathrm{rpm}$ for 5 minutes at $5{ }^{\circ} \mathrm{C}$. It was then resuspended in $10 \mathrm{ml}$ gastric solution ( $\mathrm{pH} 2-3$ ). L. paracasei and $B$. longum colony counts were determined before and after incubation for 3 hours at $37^{\circ} \mathrm{C}$, and the results were expressed as differences between the two observations.

\subsection{Statistical analysis}

Cheese samples were studied with two replications and three parallels, and the analysis of variance (ANOVA) was performed. The data were analyzed using SPSS version 15. Data from ANOVA were considered significant at $\mathrm{p}<0.05$ level based on the Duncan's multiple comparison test.

\section{Results and discussion}

It has been detected that while the starter culture number was $3,03 \times 10^{9}$ in the $90^{\text {th }}$ day, $4,90 \times 10^{7} \mathrm{cfu} / \mathrm{g}$ and that after the $180^{\text {th }}$ day it has fallen to $3,2 \times 10^{5} \mathrm{cfu} / \mathrm{g}$ and that this difference observed is important in respect of storage period $(P<0.05)$. When the changes in the cheese culture number in $\mathrm{MKP}+\mathrm{F}$ and $\mathrm{MKP}+\mathrm{I}$ cheese samples, as it is with MKP sample, after the $60^{\text {th }}$ day, increases in important amounts have been observed and, it has been detected that this number has fallen to $10^{5} \mathrm{cfu} / \mathrm{g}$ level after the $180^{\text {th }}$ day, it has been detected that while the starter culture number in $\mathrm{MKP}+\mathrm{F}$ and $\mathrm{MKP}+\mathrm{I}$ cheese samples produced in our experiment was, at the beginning, $3,65 \times 10^{9} \mathrm{cfu} / \mathrm{g}$ and $3,25 \times 10^{9} \mathrm{cfu} / \mathrm{g}$, after the $180^{\text {th }}$ day it has fallen to $3,20 \times 10^{5} \mathrm{cfu} / \mathrm{g}$ and $3,21 \times 10^{5} \mathrm{cfu} / \mathrm{g}$ level. After statistical evaluation, this difference in terms of storage period has been found important $(P<0.05)$.

\subsection{The resistance of starter cultures to barriers}

In intestinal system, skin, urogenital system, mouth, nose vacancies, shortly in every part of the body that has convenient conditions for bacteria to survive under the exterior environmental effects, bacteria, numerous in number and variety, survive. The promotion of the physiological balance of the system by healthy microorganisms in intestinal system is called "probiosis" and those microorganisms are called "probiotic microorganisms" (Zendeboodi et al., 2020). It is clearly seen from the table (Table 1) that the resistance of the probiotic bacteria used as culture in the experiment to biological barriers is more enduring compared to lactic acid bacteria which are used in the cheese production and which are composed of Lactococcus.

\subsection{Tolerance to gastric liquids}

The resistances of the lactic acid bacteria used in cheese production, in both of $\mathrm{pH}$, to gastric secretion are found to be lower when compared with probiotic bacteria. This

Table 1. The resistance of starter cultures to barriers.

\begin{tabular}{|c|c|c|c|c|c|c|c|c|c|c|}
\hline & \multicolumn{2}{|c|}{$\begin{array}{c}\text { Tolerance to gastric liquids } \\
(\mathrm{cfu} / \mathrm{g})\end{array}$} & \multicolumn{3}{|c|}{ Resistance to Bile Salts (\%) } & \multicolumn{4}{|c|}{ Deconjugation of Bile Salts } & \multirow{2}{*}{$\begin{array}{c}\text { Hydrophobicity } \\
\% \mathrm{H}\end{array}$} \\
\hline & $\mathrm{pH}: 2,0$ & $\mathrm{pH}: 3,0$ & $\% 0,3$ & $\% 0,5$ & $\% 1,0$ & TC & TDC & GC & GDC & \\
\hline L.paracasei & $5,7 \pm 0,62$ & $3,7 \pm 0,94$ & $86,0 \pm 6,20$ & $73,4 \pm 6,40$ & $60,3 \pm 5,98$ & g & g & + & - & $18,9 \pm 3,54$ \\
\hline B.longum & $>6,0 \pm 0,57$ & $2,6 \pm 0,93$ & $19,0 \pm 7,01$ & $10,8 \pm 6,45$ & $5,1 \pm 6,85$ & g & $\mathrm{g}$ & + & + & $24,8 \pm 6,40$ \\
\hline
\end{tabular}

g: grow wg: weak grow +: grow and Deconjugation of Bile Salts 
change has been much apparent in $\mathrm{pH} 3,0$, the susceptibility to gastric liquids in experimental cheese has been more apparent especially in the first 60 days of storage. In the later periods it has been retained that the cultures have gained reistance to acid circumstances and that the decreases in the numbers of the probiotic and lactic cultures has been slowing down according to their decrease levels in the beginning (Table 2). Among the bacteria used, it has been seen that Lactobacillus paracasei is more resistant. For this reason, today, it is observed that combined with probiotic bacteria, lactic acid bacteria are widely used in especially the production of fermented milk products and the production of various cheeses. But, it has been emphasized by various researchers that the logarithmic decrease levels of the mentioned bacteria change is important criteria in stomach and digestion system which is a powerful acidic environment; therefore that the resistance level of human beings is one of the most important criteria in the selection of probiotic microorganisms (Picot \& Lacroix 2003, Madureira et al., 2005; Devi et al., 2015; Zendeboodi et al., 2020).

\subsection{Resistance to Bile Salts}

Bile is formed by watery blend of organic (bile salts, cholesterol, phospholipids, bilirubin) and inorganic (water, electrolytes) compounds and bile salts together with lecithin compose the most important constituent of bile. Bile, either directly goes to duodenum passing from liver though bile duct or if there is no requirement in the digestion system it can be stored in gall bladder. The impact of the existence of bile salts in the digestion system on lactic acid bacteria is found more important than probiotic bacteria (Devi et al., 2015; Pradeep Prasanna et al., 2019). Thus, also in each of the three concentrations experimented in our work, it has become definite the reduction in the viability levels of the lactic acid bacteria is much higher, but that their decrease levels are more limited (Table 3). On the other side, it has been emphasized by various researchers that the probiotic bacteria have the potential to stay alive in human beings bile salt physiological concentration which changes from $0,3 \%$ to $0,5 \%$, but this feature can change according to the species and stains of the bacteria. (Terpou et al., 2019). Meanwhile, in this experiment, it has been detected that the lactic acid and probiotic bacteria which have been utilized in each of the three bile concentrations have gained resistance though the ripening period. And that their resistance rates are higher in micro capsuled probiotic bacteria which are supported with probiotic and protein.

\subsection{Deconjugation of Bile Salts}

Deconjugations of bile salts by the bowel microorganisms have very important tasks like reducing of serum cholesterol level. Bile salts are secreted in order to help the absorption of fats, cholesterol, hydrophobic vitamins and other compounds that dissolve in fat, which are taken in to small intestine by food. $97 \%$ of bile salts go back to liver with enterohepatic cycle after getting reabsorbed in small intestine. Deconjugation reaction is defined as the amino acid remnants of the bile salts that compose of bile acids that are conjugated with glycine or taurine with the help of bile salt hydrolase enzymes which are composed by bowel originated bacteria that also consist of Enterococcus, Clostridium, Bifidobacterium and Lactobacillus etc. species and their hydrolization to free bile salt. Free bile acids are less miscible when compared to bile salts and they are also absorbed in far less level (Tok \& Aslim, 2007). As can be observed in the Table 4, although the bile salts show for lower inhibitory affect towards the bacteria used in the experiment, it has been detected that the mentioned bacteria usually have a lower progressing tendency in the environments that include bile salts. In the experiment, the deconjugation activity is only observed in Bifidobacterium longum in the environments that include TDC and GDC and again it has been detected that Lactobacillus paracasei totally inhibits in environments including GDC.Deconjugation activity has a very important role in the balancing and preserving of micro flora of digestion system and, also, in the balancing of serum cholesterol level. For this reason, it is stated that deconjugation of bile salts is a distinguishing and desirable feature for the selection of lactic bacteria that are going to be used for the purpose of nourishment. On the other hand, among the researchers there are different points of views on the subject; it is stated that various factors like kind, species, environment, substrate properties can change the deconjugation activities of the bacteria (Moser \& Savage, 2001; Vinderola \& Reinheimer, 2003; Rowland et al., 2018).

\subsection{Hydrophobicity}

In the digestion system of the bacteria, there are a lot of mechanisms related to the adhesion to epithelial cells. Microorganisms, because of the hydrophobic structure of their outer surface have important effect on the bacteria's getting attached to hot cells. This feature provides a very important level competing advantage in keeping the bacteria balance in human digestion system. The determination of the ability of microbial adhesion of microorganism provide the quantitative determination of the bacteria's getting attached to epithelial cells (Devi et al., 2015; Haddaji et al., 2015; Pradeep Prasanna et al., 2019). When this claim is taken into consideration, it has been detected that in our experiment Bifidobecterium longum has shown the highest rate considering the hydrophobicity feature and that this is followed by Lactococcus that form the cheese culture (Table 5).

Also it has been detected that contrary to the other features, the hydrophobicity abilities of all the cultures used in our experiment have increased in the micro encapsulated samples according to the free usage of the cultures in the later periods of ripening, the ability of adhesion has decreased. In the experiments done until today, although the hydrophobicity rates of lactic acid bacteria can be at the same level as probiotic microorganisms or can be higher than them; it is seen as a very attractive case that the number of probiotic bacteria which get attached to epithelial cells is much higher (Vinderola \& Reinheimer, 2003; Devi et al., 2015; Pradeep Prasanna et al., 2019). 


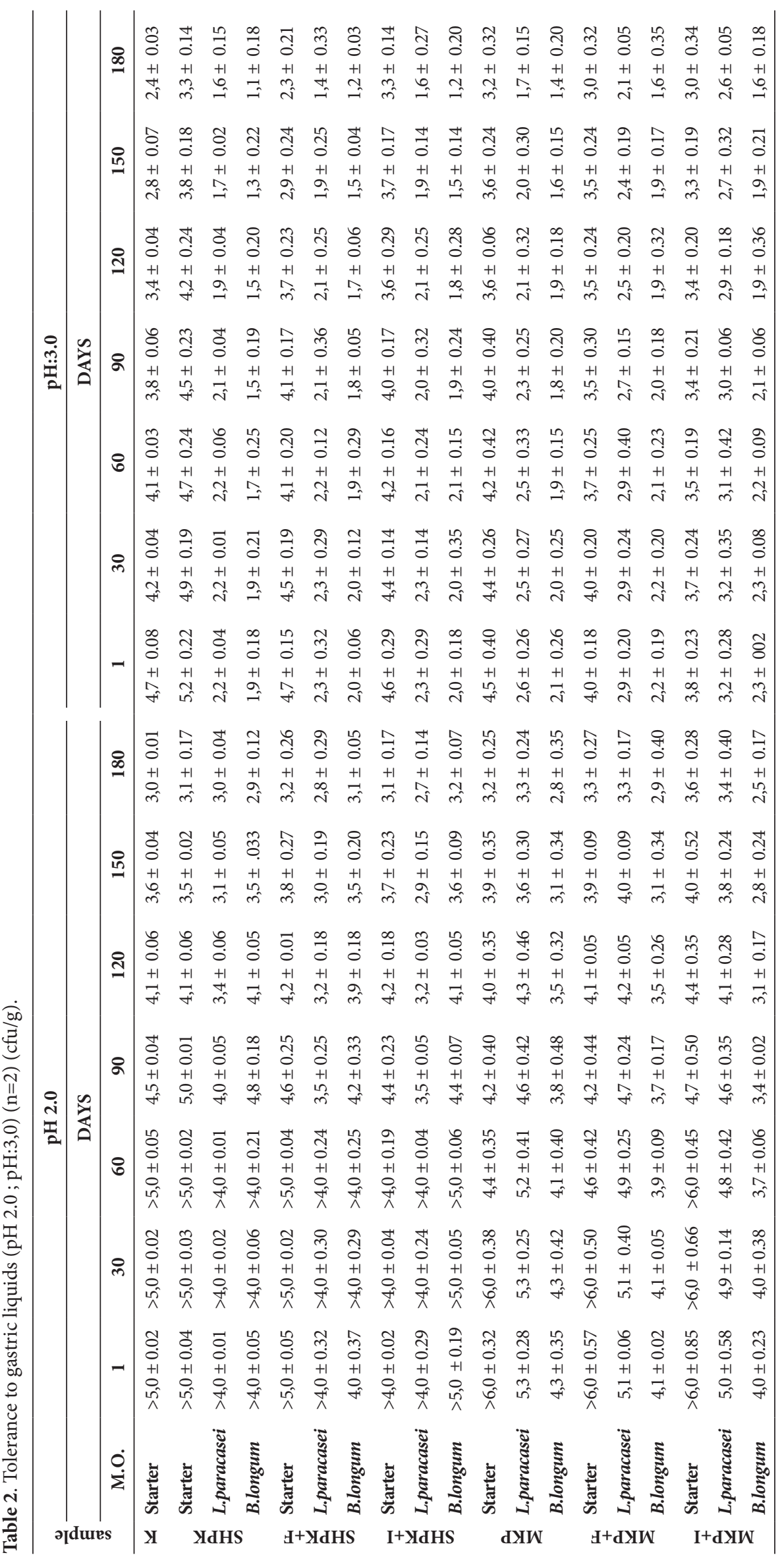




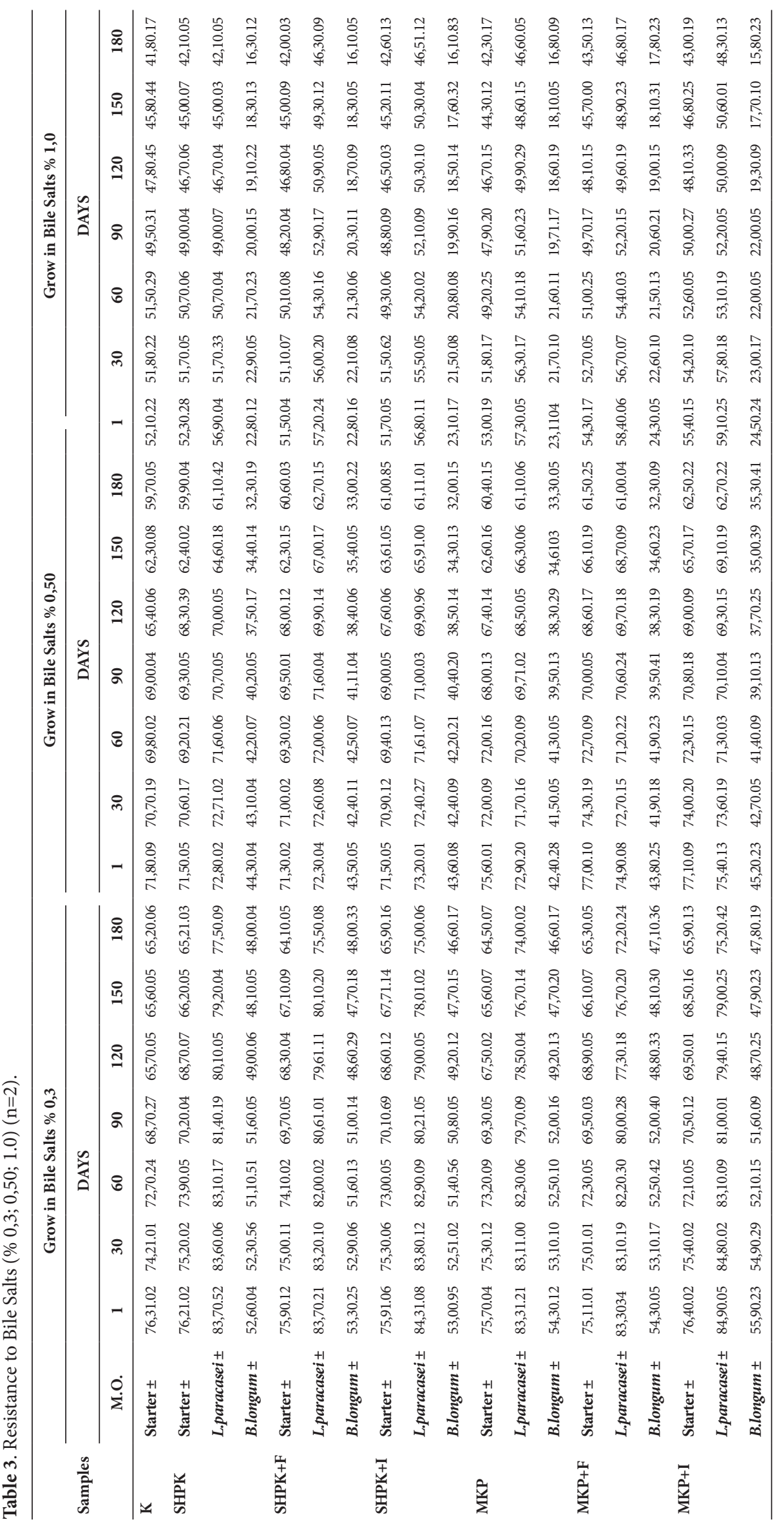




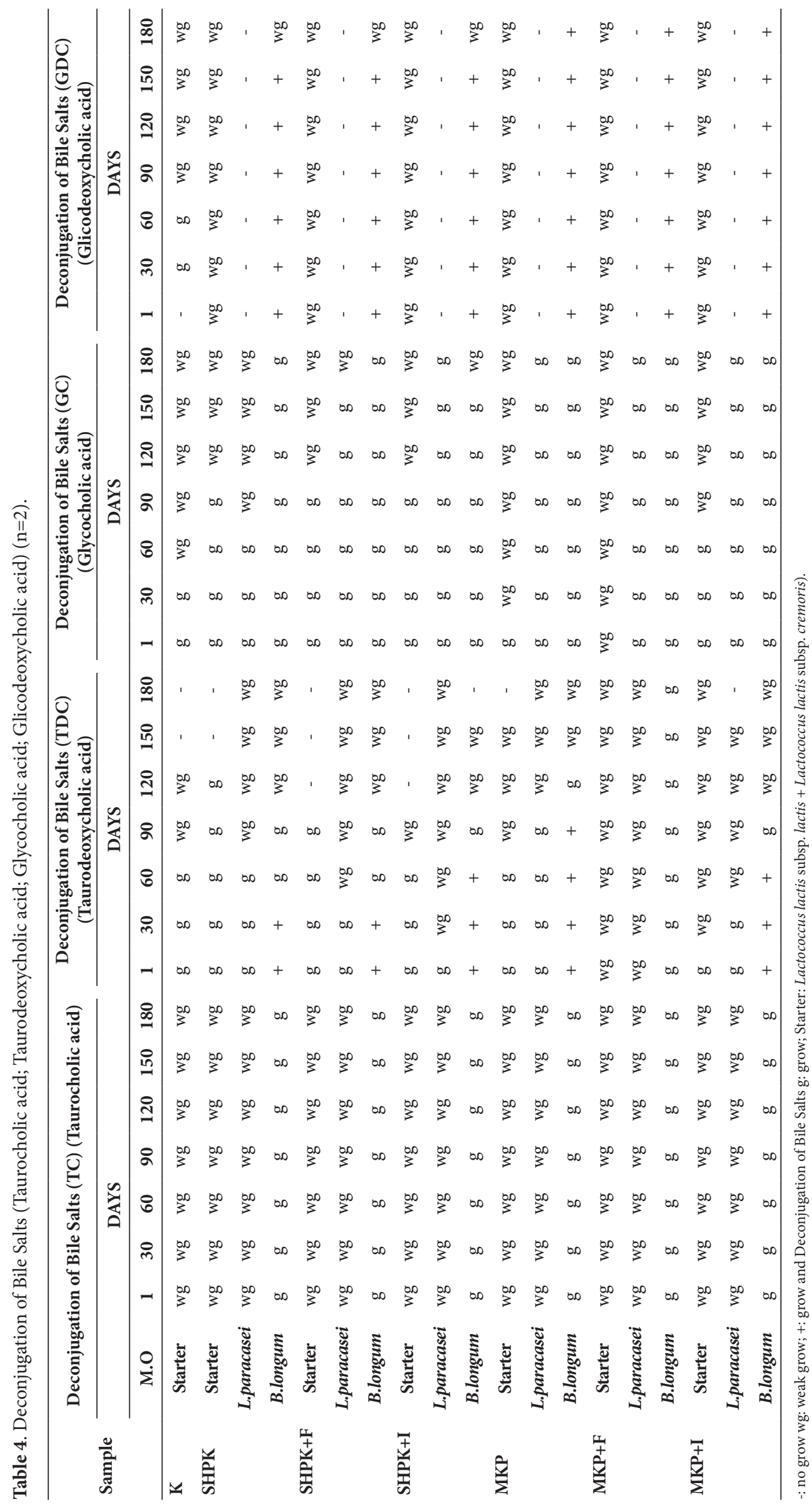


Table 5. Hydrophobicity $(n=2)(\%)$.

\begin{tabular}{|c|c|c|c|c|c|c|c|c|}
\hline \multirow{2}{*}{ SAMPLE } & \multicolumn{8}{|c|}{ \% Hydrophobicity (\%H) (DAYS) } \\
\hline & M.O. & 1 & 30 & 60 & 90 & 120 & 150 & 180 \\
\hline $\mathbf{K}$ & Starter & $23,7 \pm 2,15$ & $23,5 \pm 3,10$ & $23,0 \pm 3,02$ & $21,1 \pm 2,25$ & $19,9 \pm 1,27$ & $17,2 \pm 1,33$ & $16,0 \pm 1,40$ \\
\hline \multirow[t]{3}{*}{ SHPK } & Starter & $24,5 \pm 2,20$ & $22,9 \pm 3,41$ & $21,3 \pm 2,96$ & $19,5 \pm 2,20$ & $18,5 \pm 1,78$ & $17,6 \pm 1,20$ & $15,9 \pm 1,47$ \\
\hline & L.paracasei & $18,8 \pm 2,10$ & $18,4 \pm 2,11$ & $17,5 \pm 3,00$ & $17,1 \pm 2,22$ & $16,5 \pm 1,74$ & $15,2 \pm 1,14$ & $14,5 \pm 1,49$ \\
\hline & B.longum & $22,2 \pm 1,95$ & $22,0 \pm 3,00$ & $21,0 \pm 3,01$ & $19,9 \pm 2,24$ & $18,8 \pm 1,40$ & $18,0 \pm 1,40$ & $16,4 \pm 1,60$ \\
\hline \multirow[t]{3}{*}{ SHPK+F } & Starter & $24,0 \pm 3,05$ & $22,4 \pm 3,12$ & $21,2 \pm 3,13$ & $20,9 \pm 2,30$ & $20,2 \pm 1,45$ & $19,1 \pm 1,30$ & $18,3 \pm 1,45$ \\
\hline & L.paracasei & $19,4 \pm 2,20$ & $19,1 \pm 3,14$ & $18,3 \pm 2,99$ & $17,5 \pm 2,45$ & $16,1 \pm 1,43$ & $15,6 \pm 1,20$ & $14,6 \pm 1,48$ \\
\hline & B.longum & $22,2 \pm 2,40$ & $21,6 \pm 3,08$ & $21,5 \pm 2,83$ & $20,4 \pm 2,60$ & $19,5 \pm 1,56$ & $16,5 \pm 1,24$ & $15,4 \pm 1,14$ \\
\hline \multirow[t]{3}{*}{ SHPK+I } & Starter & $23,5 \pm 2,91$ & $21,9 \pm 3,04$ & $21,1 \pm 3,10$ & $20,5 \pm 2,74$ & $19,5 \pm 1,54$ & $18,9 \pm 1,23$ & $17,8 \pm 1,00$ \\
\hline & L.paracasei & $20,3 \pm 2,86$ & $19,8 \pm 3,06$ & $18,5 \pm 3,14$ & $17,5 \pm 2,12$ & $16,3 \pm 1,39$ & $16,2 \pm 1,28$ & $14,9 \pm 1,25$ \\
\hline & B.longum & $22,3 \pm 2,77$ & $21,7 \pm 3,10$ & $21,7 \pm 3,08$ & $20,6 \pm 2,16$ & $19,2 \pm 1,40$ & $17,1 \pm 1,30$ & $16,3 \pm 1,02$ \\
\hline \multirow[t]{3}{*}{ MKP } & Starter & $23,9 \pm 2,63$ & $22,1 \pm 3,00$ & $21,3 \pm 3,06$ & $20,5 \pm 2,20$ & $19,4 \pm 1,52$ & $18,6 \pm 1,85$ & $17,7 \pm 1,04$ \\
\hline & L.paracasei & $21,1 \pm 2,40$ & $20,7 \pm 2,88$ & $19,2 \pm 3,19$ & $18,4 \pm 2,36$ & $16,8 \pm 1,78$ & $16,4 \pm 1,40$ & $15,3 \pm 1,40$ \\
\hline & B.longum & $22,5 \pm 2,12$ & $22,1 \pm 2,50$ & $21,5 \pm 3,36$ & $21,4 \pm 2,28$ & $19,3 \pm 1,65$ & $17,7 \pm 1,36$ & $15,3 \pm 1,50$ \\
\hline \multirow[t]{3}{*}{$\mathrm{MKP}+\mathrm{F}$} & Starter & $24,7 \pm 2,00$ & $22,5 \pm 3,07$ & $21,7 \pm 3,02$ & $20,7 \pm 2,41$ & $19,3 \pm 1,35$ & $18,7 \pm 1,40$ & $16,9 \pm 1,20$ \\
\hline & L.paracasei & $21,6 \pm 3,01$ & $21,0 \pm 3,00$ & $20,3 \pm 3,40$ & $19,3 \pm 2,53$ & $17,4 \pm 1,42$ & $16,5 \pm 1,40$ & $16,0 \pm 1,30$ \\
\hline & B.longum & $23,4 \pm 2,78$ & $22,5 \pm 3,10$ & $21,5 \pm 3,04$ & $20,1 \pm 2,16$ & $18,4 \pm 1,20$ & $16,4 \pm 1,60$ & $15,6 \pm 1,36$ \\
\hline \multirow[t]{3}{*}{ MKP+I } & Starter & $24,1 \pm 2,25$ & $23,4 \pm 3,00$ & $23,1 \pm 3,08$ & $21,7 \pm 2,51$ & $20,9 \pm 1,32$ & $19,2 \pm 1,56$ & $17,1 \pm 1,31$ \\
\hline & L.paracasei & $22,1 \pm 2,17$ & $21,6 \pm 2,85$ & $21,2 \pm 3,07$ & $19,9 \pm 2,25$ & $19,2 \pm 1,20$ & $18,3 \pm 1,41$ & $17,2 \pm 1,35$ \\
\hline & B.longum & $23,7 \pm 2,30$ & $23,1 \pm 2,40$ & $21,8 \pm 3,03$ & $21,2 \pm 2,20$ & $19,7 \pm 1,30$ & $17,3 \pm 1,70$ & $16,3 \pm 1,25$ \\
\hline
\end{tabular}

Starter: Lactococcus lactis subsp. lactis + Lactococcus lactis subsp. cremoris).

\section{Conclusion}

The in vitro viability of the probiotic bacteria and microencapsulated probiotics was analyzed by simulating the gastrointestinal tract. In addition, the losses of probiotic microorganisms added in free form and probiotics subjected to microencapsulation method in high acid environment were compared. The results showed that lactic and probiotic bacteria gained resistance during maturation at all three bile concentrations, and the rate of resistance was higher in prebiotic and protein-supported microencapsulated probiotic bacteria. The resistance of lactic acid bacteria used in the cheese production to the gastric secretions was found to be lower than that of probiotic bacteria. Among the probiotic bacteria used in the cheese production, L. paracasei was found to be more resistant than $B$. longum. The intestinal microorganisms play a role in important functions, such as deconjugation of bile salts and reduction of serum cholesterol levels. In the present study, the deconjugation activity was observed only in B. longum in the media containing TDC and (GDC), while L. paracase $i$ was completely inhibited in the media containing GDC. The determination of the hydrophobicity of bacteria to evaluate the adhesion to epithelial cells in the digestive system revealed that $B$. longum had the highest hydrophobicity level, followed by Lactococcus and L. paracasei. It was found that the hydrophobicity of all cultures used in our study increased in microencapsulated samples compared with the cultures in free forms, but the adhesion ability decreased in the later stages of maturation.

\section{Acknowledgements}

This work was supported by the Scientific and Technological Research Council of Turkey (TÜBİTAK), Grant No: TÜBİTAK TOVAG 1080039.

\section{References}

Barłowska, J., Pastuszka, R.,Rysiak, A.,Król, J., Brodziak, A., KędzierskaMatysek, M., Wolanciuk, A. \& Litwińczuk Z. (2018). Physicochemical and sensory properties of goat cheeses and their fatty acid profile in relation to the geographic region of production. International Journal of Dairy Technology, 7(3), 699-708.

Castro, J. M., Tornadijo, M. E., Fresno, J. M., \& Sandoval, H. (2015). Biocheese: A food probiotic carrier. BioMed Research International, 2015, 1-11. http://dx.doi.org/10.1155/2015/723056. PMid:25802862.

Chen, K. N., Chen, M., \& Lin, C. W. (2006). Optimal combination of the encapsulating materials for probiotic microcapsules and its experimental verication (R1). Journal of Food Engineering, 76(3), 313-320. http://dx.doi.org/10.1016/j.jfoodeng.2005.05.036.

Chen, K. N., Chen, M., Lin, C. W., \& Chiu, H. Y. (2005). Optimization of incorporated prebiotics as coating materials for probiotic microencapsulation. Journal of Food Science, 70(5), 260-266. http://dx.doi.org/10.1111/j.1365-2621.2005.tb09981.x.

Dave, R. I., \& Shah, N. P. (1997). Characteristics of bacteriosin produced by Lactobacillus acidophilus LA-1. International Dairy Journal, 7(11), 707-715. http://dx.doi.org/10.1016/S0958-6946(97)00095-2. 
Devi, S. M., Archer, A. C., \& Halami, P. M. (2015). Screening, Characterization and In Vitro Evaluation of Probiotic Properties Among Lactic Acid Bacteria Through Comparative Analysis. Probiotics and Antimicrobial Proteins, 7(3), 181-192. http://dx.doi.org/10.1007/s12602-015-9195-5. PMid:26049925.

Gardiner, G. E., Bouchier, P., O'Sullivan, E., Kelly, J., Collins, J. K., Fitzgerald, G., Ross, R. P., \& Stanton, C. (2002). A spray-dried culture for probiotic Cheddar cheese manufacture. International Dairy Journal, 12(9), 749-756. http://dx.doi.org/10.1016/S09586946(02)00072-9.

Guarner, F. (2017). Probiotics and prebiotics. World Gastroenterology Organisation Global Guideline.

Haddaji, N., Mahdhi, A. K., Krifi, B., Ismail, M. B., \& Bakhrouf, A. (2015). Change in cell surface properties of Lactobacillus casei under heat shock treatment. FEMS Microbiology Letters, 362(9), 1-7. http://dx.doi.org/10.1093/femsle/fnv047. PMid:25825473.

Herman-Lara, E., Bolívar-Moreno, D., Toledo-Lopez, V. M., CuevasGlory, L. F., Lope-Navarrete, M. C., Barron-Zambrano, J. A., DíazRivera, P., \& Ramírez-Rivera, E. J. (2019). Minerals multi-element analysis and its relationship with geographical origin of artisanal Mexican goat cheeses. Food Science and Technology, 39(Suppl. 2), 517-525. http://dx.doi.org/10.1590/fst.23918.

Madureira, A. R., Pereira, C. I., Truszkowska, K., Pintado, M. E., Gomes, A. M. P., \& Malcata, F. X. (2005). Survival of probiotic bacteria in a whey cheese vector submitted to environmental conditions prevailing in the gastrointestinal tract. International Dairy Journal, 15(6-9), 921-927. http://dx.doi.org/10.1016/j.idairyj.2004.08.025.

Mituniewicz-Małek, A., Zielińska, D., \& Ziarno, M. (2019). Probiotic monocultures in fermented goat milk beverages - sensory quality of final product. International Journal of Dairy Technology, 72(2), 240-247. http://dx.doi.org/10.1111/1471-0307.12576.

Moser, S. A., \& Savage, D. C. (2001). Bile salt hydrolase activity and resistance to toxicity of conjugated bile salts are unrelated properties in lactobacilli. Applied and Environmental Microbiology, 67(8), 3476-3480. http://dx.doi.org/10.1128/AEM.67.8.3476-3480.2001. PMid:11472922.

Picot, A., \& Lacroix, C. (2003). Effects of micronization on viability andthermotolerance of probiotic freeze-dried cultures. International Dairy Journal, 13(6), 455-462. http://dx.doi.org/10.1016/S09586946(03)00050-5.

Popović-Vranješ, A., Pihler, I., Paskaš, S., Krstović, S., Jurakić, Z., \& Strugar, K. (2017). Production of hard goat cheese and goat whey from organic goat's milk. Mljekarstvo, 67(3), 177-187. http://dx.doi.org/10.15567/mljekarstvo.2017.0302.

Pradeep Prasanna, P. H., \& Charalampopoulos, D, \& Charalampopoulos, D. (2019). Encapsulation in an alginate-goats' milk-inulin matrix improves survival of probiotic Bifidobacterium in simulated gastrointestinal conditions and goats' milk yoghurt. International Journal of Dairy Technology, 72(1), 132-141. http://dx.doi.org/10.1111/1471-0307.12568.

Rezaei, A., Fathi, M., \& Jafari, S. M. (2019). Nanoencapsulation of hydrophobic and low-soluble food bioactive compounds within different nanocarriers. Food Hydrocolloids, 88, 146-162. http://dx.doi.org/10.1016/j.foodhyd.2018.10.003.

Rowland, I., Gibson, G., Heinken, A., Scott, K., Swann, J., Thiele, I., \& Tuohy, K. (2018). Gut microbiota functions: metabolism of nutrients and other food components. European Journal of Nutrition, 57(1), 1-24. http://dx.doi.org/10.1007/s00394-017-1445-8. PMid:28393285.

Sanders, M. E., Merenstein, D., Merrifield, C. A., \& Hutkins, R. (2018). Probiotics for human use. Nutrition Bulletin, 43(3), 212-225. http://dx.doi.org/10.1111/nbu.12334.

Terpou, A., Papadaki, A., Lappa, İ. K., Kachrimanidou, V., Bosnea, L. A., \& Kopsahelis, N. (2019). Probiotics in Food Systems: Significance and emerging strategies towards improved viability and delivery of enhanced beneficial value. Nutrients, 11(7), 1591. http://dx.doi. org/10.3390/nu11071591. PMid:31337060.

Tok, E., \& Aslim, B. (2007). The role of some lactic acid bacteria used as probiotics in cholesterol assimilation and bile salts deconjugation. Turkish Mycobiology Society., 37(1), 62-68.

Vinderola, C. G., \& Reinheimer, J. A. (2003). Lactic acid Starter and probiotic bacteria; a comparative in vitro study of probiotic characteristics and biological barrier resistance. Food Research International, 36(9-10), 896-904. http://dx.doi.org/10.1016/S09639969(03)00098-X.

Yao, M., Xie, J., Du, H., Mc Clements, D. J., Xiao, H., \& Li, L. (2020). Progress in microencapsulation of probiotics: a review. Comprehensive Reviews in Food Science and Food Safety, 19(2), 857-874. http://dx.doi.org/10.1111/1541-4337.12532.

Zendeboodi, F., Khorshidian, N., Mortazavian, M., \& Cruz, A. G. (2020). Probiotic: conceptualization from a new approach. Current Opinion in Food Science, 32, 103-123. http://dx.doi.org/10.1016/j. cofs.2020.03.009. 